University of Nebraska - Lincoln

DigitalCommons@University of Nebraska - Lincoln

USDA National Wildlife Research Center - Staff Publications
U.S. Department of Agriculture: Animal and Plant Health Inspection Service

2012

\title{
National surveillance for human and pet contact with oral rabies vaccine baits, 2001-2009
}

\author{
Amira A. Roess \\ Centers for Disease Control and Prevention, Atlanta, GA \\ Nancy Rea \\ Pennsylvania Department of Health \\ Edith Lederman \\ Centers for Disease Control and Prevention, Atlanta, GA \\ Virginia Dato \\ Pennsylvania Department of Health \\ Richard Chipman \\ United States Department of Agriculture
}

See next page for additional authors

Follow this and additional works at: https://digitalcommons.unl.edu/icwdm_usdanwrc

Part of the Life Sciences Commons

Roess, Amira A.; Rea, Nancy; Lederman, Edith; Dato, Virginia; Chipman, Richard; Slate, Dennis; Reynolds, Mary G.; Damon, Inger K.; and Rupprecht, Charles E., "National surveillance for human and pet contact with oral rabies vaccine baits, 2001-2009" (2012). USDA National Wildlife Research Center - Staff Publications. 1914.

https://digitalcommons.unl.edu/icwdm_usdanwrc/1914

This Article is brought to you for free and open access by the U.S. Department of Agriculture: Animal and Plant Health Inspection Service at DigitalCommons@University of Nebraska - Lincoln. It has been accepted for inclusion in USDA National Wildlife Research Center - Staff Publications by an authorized administrator of DigitalCommons@University of Nebraska - Lincoln. 


\section{Authors}

Amira A. Roess, Nancy Rea, Edith Lederman, Virginia Dato, Richard Chipman, Dennis Slate, Mary G. Reynolds, Inger K. Damon, and Charles E. Rupprecht 


\title{
Public Veterinary Medicine: Public Health
}

\section{National surveillance for human and pet contact with oral rabies vaccine baits, 2001-2009}

\author{
Amira A. Roess, PhD; Nancy Rea, PhD; Edith Lederman, MD; Virginia Dato, MD; Richard Chipman, MS; \\ Dennis Slate, PhD; Mary G. Reynolds, PhD; Inger K. Damon, MD, PhD; Charles E. Rupprecht, vMD, PhD
}

\begin{abstract}
Objective-To determine the rate and absolute number of human and pet exposures to oral rabies vaccine (ORV) bait containing liquid vaccinia rabies glycoprotein recombinant vaccine and to evaluate factors that might affect human contact with bait to modify the program and reduce human exposure to the vaccine.
\end{abstract}

Design-Retrospective analysis of surveillance data (2001 to 2009).

Sample-Reports on human and pet contact with ORV baits in states with ORV surveillance programs.

Procedures-Data were collected from passive, multistate ORV surveillance systems in Alabama, Arizona, Florida, Georgia, Maine, Maryland, Massachusetts, New Hampshire, New Jersey, New York, North Carolina, Ohio, Pennsylvania, Tennessee, Texas, Vermont, Virginia, and West Virginia. Data collected included the nature of human or pet contact with bait and vaccine, the caller's knowledge of the ORV bait program, local human population density, and other relevant demographic data.

Results-All 18 states participated in the surveillance program for at least 1 year, for a combined 68 years of observation. One thousand four hundred thirty-six calls were reported, representing 3,076 found baits (6.89/100,000 baits dropped); 296 (20\%) calls were related to human contact with ruptured bait, and 550 (38\%) involved pet contact with the bait. Six adverse events in humans were reported, one of which required hospitalization. Fifty-nine adverse events in pets were noted, all of which were nonserious.

Conclusions and Clinical Relevance-Findings from surveillance activities have been used to improve baiting strategies and minimize human and pet contact with ORV baits. Overall, human and pet contact with ORV baits was infrequent. Surveillance has led to early identification of persons exposed to ORV and rapid intervention. (J Am Vet Med Assoc 2012;240:163-168)

$R^{2}$ abies, a zoonotic disease caused by infection with RNA viruses in the family Rhabdoviridae, genus Lyssavirus, is almost always fatal in humans. ${ }^{1}$ Canine vaccination and stray animal control programs implemented in 1946 have significantly reduced domestic animal and human rabies cases in the United States from 8,384 domestic dog cases $^{2,3}$ and 33 human cases in $1946^{2,3}$ to 75 dog cases ${ }^{2,3}$ and 2 human cases in $2008^{4-6}$

ABbreViation
ORV Oral rabies vaccine

During this same period, there was a marked increase in wildlife rabies. Raccoon rabies, first identified as a concern in the 1940s, ${ }^{3}$ became endemic in the Eastern states and Southern Canada. ${ }^{7-9}$ Most reported cases of

\footnotetext{
From the Epidemic Intelligence Service, Epidemiology Program Office (Roess, Lederman), and Division of High Consequence Pathogens and Pathology, National Center for Emerging and Zoonotic Infectious Diseases (Roess, Lederman, Reynolds, Damon, Rupprecht), 1600 Clifton Rd, Centers for Disease Control and Prevention, Atlanta, GA 30333; the Pennsylvania Department of Health, 233 W Ottterman St, Greensburg, PA 15601 (Rea, Dato); and the Animal and Plant Health Inspection Service, United States Department of Agriculture, 59 Chennell Dr, Ste 7 , Concord, NH 03301 (Chipman, Slate). Dr. Roess' present address is Department of Global Health, School of Public Health and Health Sciences, George Washington University, Washington, DC 20037. Dr. Lederman's present address is STG International, 99 Canal Center Plaza, Ste 500, Alexandria, VA 22314. Dr. Rea's present address is College of Health Sciences, School of Health Sciences, Walden University, Minneapolis, MN 55401.

The findings and conclusions in this article are those of the authors and do not necessarily represent the views of the Centers for Disease Control and Prevention, the United States Department of Agriculture, or the Pennsylvania Department of Health.

Address correspondence to Dr. Rupprecht (cyr5@cdc.gov).
} 
wildlife rabies occur among raccoons (Procyon lotor), skunks (primarily Mephitis mephitis), gray foxes (Urocyon cinereoargenteus), and multiple species of bats, and these species are now the primary sources of rabies in dogs. ${ }^{8,10,11}$ Each year, an estimated 16,000 to 39,000 persons in the United States come in contact with rabid and potentially rabid animals and receive rabies postexposure prophylaxis. ${ }^{5,12}$

Rabies control measures include vaccination of domestic animals and surveillance programs to monitor rabies trends in humans and animals. Oral rabies vaccine programs were first initiated to complement traditional rabies control measures in Europe in 1977. The current USDA-licensed ORV consists of a rabies virus glycoprotein gene inserted into the thymidine kinase locus of the Copenhagen strain of vaccinia virus ${ }^{13,14, a}$; the deletion of a functional thymidine kinase results in attenuation of the virus. ${ }^{15}$ The oral vaccinia rabies glycoprotein recombinant vaccine $e^{a}$ is packaged and distributed in heat-sealed plastic packets or sachets that are coated with fishmeal or placed within a fishmeal block to entice uptake by raccoons ( $P$ lotor), gray foxes ( $U$ cinereoargenteus), and coyotes (Canis latrans). Following oral exposure to the vaccine, the animals develop neutralizing antibodies to rabies virus. The use of ORV began in Canada in 1985 and in the United States in 1990. In 1995, the USDA's National Rabies Management Program established the ORV program to prevent the further spread of wildlife rabies and eventually eliminate carnivore rabies in the United States through methods that involve the use of oral rabies vaccination targeting wildlife. ${ }^{16}$ It is anticipated that as the number of vaccinated animals in the population increases, development of herd immunity will minimize the spread of disease to other wildlife, domestic animals, and humans. Oral rabies vaccine programs to combat the spread of raccoon rabies are currently ongoing in 16 eastern states; in Texas and Arizona, baits are distributed for rabies control in gray foxes and coyotes.

Vaccinia virus, the viral component of the oral vaccinia rabies glycoprotein recombinant vaccine,${ }^{a}$ is an orthopoxvirus used as the viral vector of the vaccine. The vaccinia virus strain used in the ORV ${ }^{a}$ has been attenuated. Nevertheless, human (percutaneous) exposure to ruptured sachets can result in vaccinia virus infection. ${ }^{17,18}$ Severe outcomes are possible among persons who are immunocompromised and for those with atopic dermatitis, exfoliative dermatologic conditions, and other conditions considered to be contraindications to smallpox vaccination. . $^{14,17,18}$

Since 1990, > 200 million doses of the ORV ${ }^{a}$ have been distributed in the United States. However, reports of human and domestic animal contact with ORV baits have been relatively rare. ${ }^{8,19}$ In Pennsylvania, human exposure to the liquid vaccine was reported to occur via dogs that find a bait and puncture the sachet when humans attempt to remove the bait from the dog's mouth. ${ }^{19}$

Oral rabies vaccine bait distribution areas and methods (aerial or ground hand baiting) are selected to optimize opportunities to vaccinate wildlife but minimize the chance of contact with non-target species, such as humans and pets. Fixed-wing aircraft are the most effective means for distributing large numbers of
ORV baits. Hand baiting is important in urban and suburban areas, where raccoon (P lotor) densities may be elevated and there may be limited habitat available for baiting as well as safety risks associated with distributing baits by air. Prior to baiting, communication campaigns such as press releases, public service announcements, and ORV media days at local airports where ORV operations are being coordinated are conducted to raise awareness. In addition, printed on each bait is a toll-free telephone number for the federal, state, or local agency supporting the local ORV program. If a person finds bait, he or she can call that number to obtain information about the ORV or to report (human or pet) contact with bait. This information forms the basis of a bait contact passive surveillance system.

State-based bait programs consist of 1 to 2 baiting distributions/y, and surveillance for human and pet contact with bait is conducted annually. Surveillance data have been used by agencies involved in ORV programs to improve local communications programs, modify baiting strategies, and reduce human and pet contact with baits by reducing aerial baiting in areas of high human population density and through better habitat targeting through hand baiting. The purpose of the study reported here was to determine the number of human and pet contact events with baits containing the ORV from 2001 to 2009. In this report, we also describe a severe adverse event in an immunocompromised individual reported to the surveillance system to illustrate how the surveillance system led to the prompt identification of the patient.

\section{Materials and Methods}

Surveillance system-Since 2001, the USDA Wildlife Services Program has maintained a surveillance system of human and pet contact with ORV baits. Reports of human or pet contact with baits occur principally via 1 of 2 mechanisms: from a citizen who has found the bait and calls the toll-free number printed on the baits or from federal or local agencies that were contacted after a bait was found. Additional information about the nature and circumstances of the contact is then collected by personnel in the appropriate local agency (typically a State or County Health Department). The nature of the information collected by individual jurisdictions varies but usually includes the circumstances surrounding bait discovery, where it was found, how it was retrieved, and whether the sachet containing the vaccine was punctured. At the end of each ORV baiting season, federal and local offices in participating states complete a standardized surveillance questionnaire, which is designed to capture reports of human and pet contact with the bait. Eighteen states have participated in this surveillance system: Alabama, Arizona, Florida, Georgia, Maine, Maryland, Massachusetts, New Hampshire, New Jersey, New York, North Carolina, Ohio, Pennsylvania, Tennessee, Texas, Vermont, Virginia, and West Virginia.

Statistical analysis-Surveillance forms were created by use of commercial software, ${ }^{\mathrm{b}}$ and data were analyzed with statistical software. ${ }^{c}$ Surveillance data were analyzed to determine the rates of human and pet exposure 
to ORV baits from 2001 to 2009. Rates of calls, exposures, and outcomes per 100,000 baits distributed are presented. Frequencies for particular locations where baits were found, descriptions of the nature of human and pet contact, and a summary of adverse events involving humans and pets were evaluated. Rate ratios were calculated to determine differences in the distribution of responses between geographic variables potentially affecting human contact with bait (bait density, human population density, and bait distribution method) and $P$ values are reported. Low population density was categorized as $<150$ people/ $\mathrm{km}^{2}$, high population density as $\geq 150$ people $/ \mathrm{km}^{2}$, low bait density as $\leq 75$ bait-vaccine units $/ \mathrm{km}^{2}$, and high bait density as $>75$ bait-vaccine units $/ \mathrm{km}^{2}$.

\section{Results}

From 2001 through 2009, > 80 million ORV baits were distributed in 18 states (Table 1). Number of years participating in the surveillance system during this period differed among states; West Virginia, Ohio, Vermont, New Hampshire, Texas, and New York each had program activities for the length of the surveillance period $(n=9)$. Time with ORV bait program activities was 8 years in Maryland, Pennsylvania, Virginia, Tennessee, and New Jersey; 7 years in Maine; 6 years in Florida, Georgia, and Alabama; and 5 years in North Carolina, Massachusetts, and Arizona. The cumulative number of baits distributed between 2001 and 2009 ranged from 133,449 in Arizona to $24,172,750$ in Texas. The surveillance program captured information for a combined 68 years of observation $(50.7 \%) ; 44,635,548$ baits were distributed during this observation period, and 3.51 calls/100,000 baits distributed were reported (Table 2 ). The rate of calls to the helpline and the rate of bait incidences varied over the surveillance period. The rate (per 100,000 baits distributed) of calls regarding pet contact with bait (2.53) was higher than the rate of calls regarding human contact with bait $(0.47)$.
During the study period, there were 1,436 calls to the helpline and 3,076 baits were reported to have been found (6.89/100,000 baits distributed). The rate of baits found peaked in 2004 and then decreased to below 2001 values. Two hundred ninety-six (20\%) calls were related to human contact with ruptured baits, and 550 (38\%) involved pet contact with the bait, which were not mutually exclusive. The rates for pets finding bait, pets ingesting bait, and adverse events were $1.23,0.70$, and $0.08 / 100,000$ baits distributed, respectively. Callers reported that pets had clinical signs including lethargy, diarrhea, and vomiting. The rates of possible human exposure (defined as skin

Table 2-Number and rates (per 100,000 ORV baits distributed) of calls received during a 9-year (2001 through 2009) multistate surveillance period and rates of human and pet contact.

\begin{tabular}{|c|c|c|c|}
\hline State & $\begin{array}{c}\text { Rate of } \\
\text { calls (No.) }\end{array}$ & $\begin{array}{l}\text { Rate of human } \\
\text { contact (No.)* }\end{array}$ & $\begin{array}{c}\text { Rate of pet } \\
\text { contact (No.)* }\end{array}$ \\
\hline $\begin{array}{l}\text { Alabama } \\
\text { Arizona } \\
\text { Florida } \\
\text { Georgia } \\
\text { Maine } \\
\text { Maryland } \\
\text { Massachusetts } \\
\text { New Hampshire } \\
\text { New Jersey } \\
\text { New York } \\
\text { North Carolina } \\
\text { Ohio } \\
\text { Pennsylvania } \\
\text { Tennessee } \\
\text { Texas } \\
\text { Vermont } \\
\text { Virginia } \\
\text { West Virginia } \\
\text { Total }\end{array}$ & $\begin{array}{c}3.46(37) \\
0.77(1) \\
1.12(68) \\
1.46(5) \\
16.19(5) \\
8.4(13) \\
38.77(57) \\
9.31(27) \\
0(0) \\
3.42(103) \\
0.95(4) \\
4.81(412) \\
6.76(431) \\
6.14(79) \\
0.13(8) \\
2.65(36) \\
0.30(7) \\
1.29(143) \\
\mathbf{3 . 5 1}(1,436)\end{array}$ & $\begin{array}{l}0.09(1) \\
0.00(0) \\
0.49(4) \\
0.00(0) \\
0.00(0) \\
0.00(0) \\
6.59(6) \\
0.00(0) \\
0.00(0) \\
N A \\
0.00(0) \\
2.02(45) \\
0.84(16) \\
0.08(1) \\
0.00(0) \\
0.72(7) \\
0.33(2) \\
0.28(7) \\
0.47(89)\end{array}$ & $\begin{array}{l}1.60(18) \\
0.00(0) \\
4.95(40) \\
0.58(2) \\
1.66(2) \\
5.82(9) \\
54.94(50) \\
0.00(0) \\
0.00(0) \\
\mathrm{NA} \\
0.24(1) \\
7.59(169) \\
4.10(78) \\
3.58(46) \\
0.08(5) \\
2.48(24) \\
0.33(2) \\
1.28(32) \\
2.53(478)\end{array}$ \\
\hline \multicolumn{4}{|c|}{$\begin{array}{l}\text { *Because of missing data, only information on rates of human } \\
\text { and pet contact reported to the surveillance programs in } 2008 \text { and } \\
2009 \text { was included. } \\
\text { NA = Not available. }\end{array}$} \\
\hline
\end{tabular}

Table 1-Multistate vaccination programs that used oral vaccinia rabies glycoprotein recombinant vaccine $e^{a}$ in the United States from 2001 to 2009.

\begin{tabular}{|c|c|c|c|c|}
\hline State (year program began) & $\begin{array}{l}\text { No. of y of ORV program } \\
\text { activities (No. of y } \\
\text { captured in surveillance) }\end{array}$ & Area $\left(\mathrm{km}^{2}\right)$ & $\begin{array}{l}\text { Population } \\
\text { density }(\mathrm{No} \text {. of } \\
\text { people/km²)* }\end{array}$ & $\begin{array}{l}\text { Total No. of ORV baits } \\
\text { distributed (No. distributed } \\
\text { during surveillance) }\end{array}$ \\
\hline Alabama (2004) & $6(2)$ & 8,569 & 190.67 & $4,279,161(1,070,029)$ \\
\hline Arizona (2005) & $5(2)$ & 1,400 & 141.98 & $135,449(129,600)$ \\
\hline Florida (1995) & $6(6)$ & 8,185 & 828.83 & $3,767,453(3,025,449)$ \\
\hline Georgia (2004) & $6(2)$ & 1,451 & 210.07 & $686,868(342,487)$ \\
\hline Maine (2003) & 7 (4) & 690 & 366.63 & $632,123(216,123)$ \\
\hline Maryland (2002) & $8(2)$ & 1,086 & 1336.81 & $2,172,105(154,710)$ \\
\hline Massachusetts (2008) & $5(2)$ & 988 & 223.64 & $514,823(147,036)$ \\
\hline New Hampshire (1997) & $9(4)$ & 299 & 106.93 & $1,348,886(429,605)$ \\
\hline New Jersey (1992) & 8 (1) & 480 & 199.54 & $359,200(40,000)$ \\
\hline New York (1995) & $9(2)$ & 20,003 & 365.61 & $11,135,545(3,015,732)$ \\
\hline North Carolina (2005) & $5(2)$ & 2,917 & 145.71 & $924,273(419,455)$ \\
\hline Ohio (1998) & $9(9)$ & 13,913 & 232.84 & $8,559,676(8,559,676)$ \\
\hline Pennsylvania (2002) & 8 (7) & 12,637 & 266.63 & $7,595,083(6,374,743)$ \\
\hline Tennessee (2002) & $8(2)$ & 11,570 & 119.03 & $3,938,225(1,286,637)$ \\
\hline Texas (1995) & $9(2)$ & 107,599 & 21.19 & $24,172,750(6,026,998)$ \\
\hline Vermont (1997) & $9(4)$ & 7,255 & 54.16 & $2,245,992(1,358,616)$ \\
\hline Virginia (2002) & $8(7)$ & 5,053 & 60.67 & $2,619,735(2,299,344)$ \\
\hline West Virginia (2001) & $9(8)$ & 20,085 & 59.47 & $11,127,540(11,127,540)$ \\
\hline Total & 134 (68) & 224,182 & 138 & $86,214,887(44,635,548)$ \\
\hline
\end{tabular}

*Population density of areas baited from 2008 census data. 
contact with bait), probable skin exposure defined as skin or mucosa contact with broken bait, and adverse events were $0.66,0.04$, and $0.007 / 100,000$ baits distributed, respectively $(n=6)$.

Adverse events in humans reported by callers included rash, itchy skin, redness, and swelling. All of these involved someone having handled bait that had been ruptured by a pet dog. Five of the adverse events in humans involved skin rashes or dermatologic reactions, presumably to the fishmeal bait, and 1 resulted in a serious vaccinia virus infection. ${ }^{20}$ Briefly, the Pennsylvania Department of Health received a report that a 35-yearold woman, who was taking immunosuppressive medications to control symptoms of inflammatory bowel disease, picked up a bait ruptured by her dog. At the time, the woman had been picking blackberries and there were freshly abraded patches of skin on her right hand and wrist. Liquid vaccine leaked onto the abraded skin. When she returned home, after approximately 30 minutes, she was able to call the ORV helpline number. The ORV helpline contacted a Public Health Physician at her state health department who was concerned be-

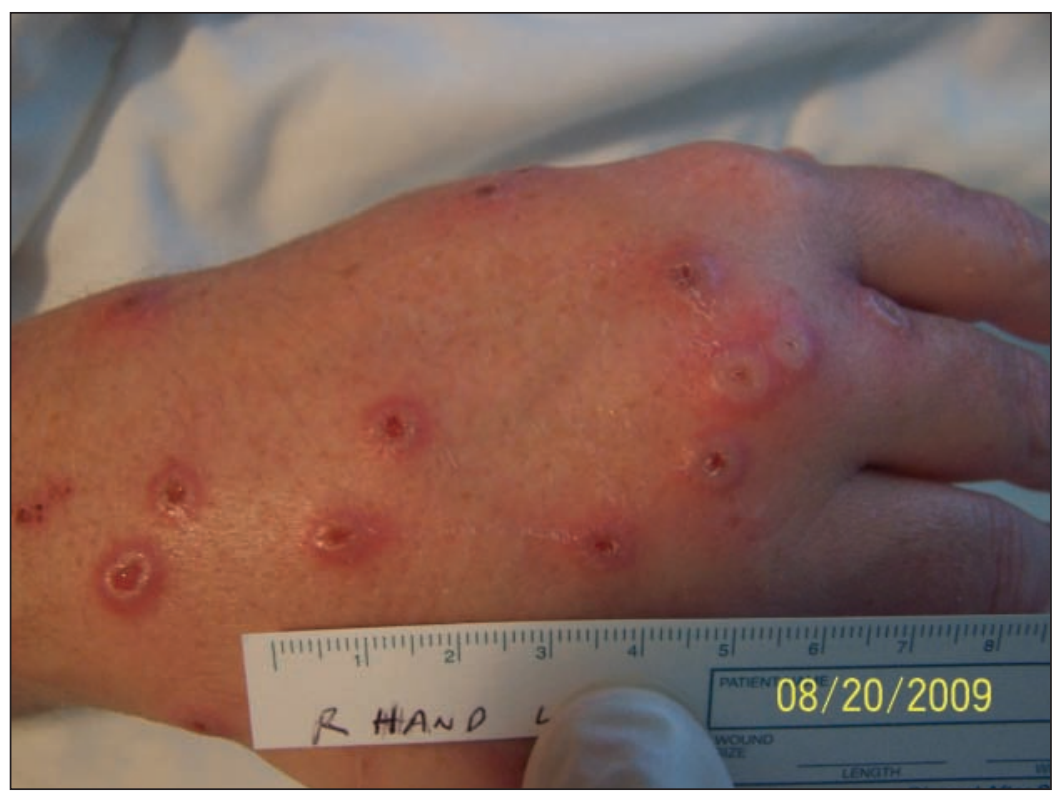

Figure 1-Photograph of female human patient (age, 35 years) receiving immunosuppressive medications for inflammatory bowel disease, with vaccinia virus lesions and pronounced redness and edema of her right hand on day 10 after contact with an animal ORV bait. cause of the specific immunosuppressive agents taken and the type and degree of exposure. The women received immediate instructions on what to look for and who to call if any lesions developed. Within 24 hours after the call, the women's personal physicians and experts at the CDC were notified. Pictures of the injuries were obtained, and serologic analysis to obtain baseline data was performed. On day 4 following the exposure, she called again because several red papules appeared and she was subsequently diagnosed with vaccinia infection $^{20}$ (Figure 1).

Of 1,272 callers, 347 (27\%) were aware of the ORV baiting program, and 928 of 1,404 (66.1\%) had called the ORV helpline number. Forty-eight percent of baits were found on residential property, $42.7 \%$ were retrieved by pets, $5.8 \%$ were found on streets, and the rest were found in wooded areas. Human $\left(\mathrm{R}^{2}=7.8\right.$; $P=0.024)$ and pet $\left(\mathrm{R}^{2}=10.96 ; P=0.043\right)$ contact with bait was considerably higher in areas of high human population densities ( $\geq 150$ people $/ \mathrm{km}^{2}$ ), compared with contact in areas of low population densities (< 150 people $/ \mathrm{km}^{2}$; Table 3 ). Ground baiting is the preferred method of bait distribution in areas with high human population densities, and baits are distributed at a low density ( $\leq 75$ bait-vaccine units/ $\mathrm{km}^{2}$ ). Therefore, human and pet contact with bait increased as the percentage of ground baiting increased. Contact rates for both humans and domestic animals did not increase with higher bait density, presumably because baits are distributed at higher density in areas with lower human population density.

\section{Discussion}

Since 2000, > 100 million doses of the ORV have been distributed in the United States. The present study found that during the period from 2001 through 2009, the rate of calls to the helpline remained relatively constant; a small increase was observed from 2007 through 2009, which may have been related to sizable increases in surveillance participation. Nominally higher rates of found baits were observed during the pe-

Table 3-Human and pet contact rates per 100,000 ORV baits distributed in 2008 in all states excluding Arizona, by human population and bait density.

\begin{tabular}{|c|c|c|c|c|}
\hline Variable & $\begin{array}{c}\text { Rate ratio ( } 95 \% \text { CLs) } \\
\text { of human contact } \\
\text { with bait }\end{array}$ & $P$ value & $\begin{array}{c}\text { Rate ratio (95\% CLs) } \\
\text { of pet contact } \\
\text { with bait }\end{array}$ & $P$ value \\
\hline $\begin{array}{l}\text { Population density (high vs low) } \\
\text { Bait density (high vs low) }\end{array}$ & $\begin{array}{l}7.80(1.31-46.5) \\
0.37(0.116-1.21)\end{array}$ & $\begin{array}{l}0.024 \\
0.101\end{array}$ & $\begin{array}{c}10.96(1.08-111.35) \\
0.25(0.05-1.23)\end{array}$ & $\begin{array}{l}0.043 \\
0.089\end{array}$ \\
\hline $\begin{array}{l}\text { Ground baiting } \\
\geq 85 \% \\
10 \%-85 \% \\
<10 \%\end{array}$ & $\begin{array}{c}9.00(3.44-23.53) \\
\text { Referent } \\
0.13(0.01-1.91)\end{array}$ & $\begin{array}{r}<0.001 \\
0.137\end{array}$ & $\begin{array}{c}11.28(3.57-35.64) \\
\text { Referent } \\
0.05(0.00-8.43)\end{array}$ & $\begin{array}{r}<0.001 \\
0.249\end{array}$ \\
\hline
\end{tabular}


riod from 2001 to 2004; however, this may have been related to an increase in the number of bait distribution programs, given that 13 states initiated ORV bait programs during this period. Historically, the highest rates of found baits have been observed during the inaugural bait program in individual states. Enhanced surveillance during this period is essential for modifications to future bait distribution plans.

Surveillance data suggest that human and domestic animal contact with ORV baits has been and continues to be rare. In the present study, the rate of reported contact with baits (1.29/100,000 baits distributed) was similar to those that have been found in other studies, which have ranged from 0.12 to 50 reports/100,000 baits distributed. ${ }^{8,14,19,21}$ Pets continue to be the major source of human exposure to the liquid vaccine component of ORV baits. ${ }^{14,19}$ Most baits were found by pet dogs, and all of the adverse events in humans were linked to retrieving bait from a pet dog. A published analysis ${ }^{19}$ of local surveillance data from Pennsylvania in 2003 demonstrated similar rates $(66 / 70$ pets that found baits were dogs). ${ }^{19}$ Furthermore, 7 of 8 human exposures to vaccine occurred after a dog had ruptured the sachet containing the vaccine in baits. ${ }^{19}$ Another analysis in Ohio indicated that 18 of 20 reports of probable exposures to vaccine involved dogs; 3 of 20 reports involved persons with health conditions that are contraindications for vaccinia virus vaccination. ${ }^{14}$

The vaccinia rabies glycoprotein virus is a selfreplicating attenuated agent that may cause adverse events. Early identification of persons at high risk for developing serious vaccinia virus infection is important to avoid adverse outcomes. Surveillance and early detection led to prompt identification of an immunocompromised individual who was exposed to vaccine liquid and allowed for a timely intervention. Medical personnel were alerted of possible vaccinia infection prior to symptom onset, and rapid implementation of treatment was possible.

In a previous study, ${ }^{8}$ increased human population density was also significantly related to increased rates of human and pet contact with the baits. The ORV program uses ground (hand) baiting in areas with higher human population density to reduce the risk of human exposure. Given that there is a consequential relationship between increased human and pet contact in areas with the highest ground baiting, low numbers of bait contacts may not be completely avoidable (Table 3). Just as surveillance during inaugural programs was important to inform bait distribution plans to lower numbers of found baits, it remains essential in identifying areas that may have demographic or other changes from season to season that lead to an increase in found baits. Continual surveillance is important for further refinement of bait distribution and identification of higher-than-expected rates of found baits.

Community outreach is an integral component of ORV programs. The extent to which outreach proved useful to those individuals who ultimately found baits (callers) could not be determined from the surveillance data summarized in this study because these data are not routinely collected at the state level. However, we did find that a large number of callers $(n=598)$ re- ported that they did not know about ORV activities. Increased media outreach, public service announcements, and newspaper advertisements may improve knowledge of the baiting campaigns, ${ }^{8,19}$ as in Pennsylvania, where a sharp decrease in reports of bait contact from 2003 to 2004 (from 6.1 to 2.9/100,000 baits distributed) was attributed to modifications made to the program, including an increase in media outreach in smaller markets and increased hand baiting. ${ }^{19}$ The establishment of communication campaigns that support surveillance objectives through evolving social media such as microblogging and social networking services is currently under consideration.

The adverse event described in the present report is the second documented case of vaccinia virus infection associated with the ORV. The first instance involved a pregnant 28-year-old Ohio resident with epidermolytic hyperkeratosis who was bitten while pulling a ruptured bait from her dog's mouth. ${ }^{14}$ During the course of a 34day infection, she developed swelling, erythema, left axillary adenopathy, pustules, and necrotic scabs; her skin ultimately healed, and the pregnancy followed a normal progression. ${ }^{14}$ Both documented instances of human vaccinia virus infections caused by the ORV occurred after baits were found and the sachets were punctured by dogs, ${ }^{14,20}$ and all adverse events in humans involved interaction with pet dogs that found baits. ${ }^{8,14,19-21}$ These observations suggest that owners should not attempt to remove baits from their dog's mouth and instead should use gloves or plastic bags to pick up and examine baits.

Results of data analysis in this report have several potential limitations. First, this is a passive surveillance system that relies on voluntary reporting, and it is likely to underestimate the number of contacts with bait. Information collected from individuals calling differs among states; each state has its own surveillance form, and type of information and level of detail differ among states. Enhanced standardization of protocols is recommended. Between 2005 and 2007, half of the ORV baiting programs did not complete reporting to the surveillance system. Increased follow-up to all states resulted in a sizable increase of participation, up to $95 \%$ in 2008 and 2009.

The surveillance system in place has been useful in collecting timely pet and human ORV exposure data. Refinements and standardization of the surveillance system are needed, particularly at the individual program level. Communication campaigns are an essential method to educate the public about ORV and the associated risk of contact with baits and vaccine, and these should be modified during baiting activities to enhance outreach.

\footnotetext{
a. Raboral V-RG, Merial Inc, Duluth, Ga.

b. Adobe LiveCycle, Adobe Systems Inc, San Jose, Calif.

c. SPSS, version 17.0, SPSS Inc, Chicago, Ill.
}

\section{References}

1. Noah DL, Drenzek CL, Smith JS, et al. Epidemiology of human rabies in the United States, 1980 to 1996. Ann Intern Med 1998;128:922-930.

2. Jenkins SR, Perry BD, Winkler WG. Ecology and epidemiology of raccoon rabies. Rev Infect Dis 1988;10(suppl 4):S620-S625. 
3. Jenkins SR, Winkler WG. Descriptive epidemiology from an epizootic of raccoon rabies in the Middle Atlantic States, 19821983. Am J Epidemiol 1987;126:429-437.

4. Blanton J, Robertson K, Palmer D, et al. Rabies surveillance in the United States during 2008. J Am Vet Med Assoc 2009;235:676-689.

5. Blanton JD, Hanlon CA, Rupprecht CE. Rabies surveillance in the United States during 2006. J Am Vet Med Assoc 2007;231:540-556.

6. Velasco-Villa A, Messenger S, Orciari L, et al. Identification of new rabies virus variant in Mexican immigrant. Emerg Infect Dis 2008;14:1906-1908.

7. Krebs JW, Strine TW, Smith JS, et al. Rabies surveillance in the United States during 1994. J Am Vet Med Assoc 1995;207:1562-1575.

8. McGuill MW, Kreindel SM, DeMaria A Jr, et al. Human contact with bait containing vaccine for control of rabies in wildlife. Am Vet Med Assoc 1998;213:1413-1417.

9. Rupprecht CE, Smith JS, Fekadu M, et al. The ascension of wildlife rabies: a cause for public health concern or intervention? Emerg Infect Dis 1995;1:107-114.

10. Krebs JW, Mandel EJ, Swerdlow DL, et al. Rabies surveillance in the United States during 2004. J Am Vet Med Assoc 2005;227:1912-1925.

11. Meehan SK. Rabies epizootic in coyotes combated with oral vaccination program. J Am Vet Med Assoc 1995;206:1097-1099.

12. Krebs JW, Smith JS, Rupprecht CE, et al. Rabies surveillance in the United States during 1997. J Am Vet Med Assoc 1998;213:1713-1728.
13. Hanlon CA, Niezgoda M, Hamir AN, et al. First North American field release of a vaccinia-rabies glycoprotein recombinant virus. J Wildl Dis 1998;34:228-239.

14. Rupprecht C, Blass L, Smith K, et al. Human infection due to recombinant vaccinia-rabies glycoprotein virus. New Engl J Med 2001;345:582-586.

15. Rupprecht C, Hanlon C, Koprowski H. General considerations in the use of recombinant rabies vaccines for oral immunization of wildlife. In: Laboratory techniques in rabies. 4th ed. Geneva: World Health Organization, 1996;341-346.

16. Rupprecht CE, Hanlon CA, Slate D. Oral vaccination of wildlife against rabies: opportunities and challenges in prevention and control. Dev Biol (Basel) 2004;119:173-184.

17. CDC. Vaccinia vaccine: recommendations of the Advisory Committee on Immunization Practices (ACIP), 2001. MMWR Morb Mortal Wkly Rep 2001;50:1-25.

18. Hanlon CA, Niezgoda M, Shankar V, et al. A recombinant vaccinia-rabies virus in the immunocompromised host: oral innocuity, progressive parenteral infection, and therapeutics. Vaccine 1997; 15:140-148.

19. Dato VM, Rupprecht C. Rabies vaccine baits, Pennsylvania. Emerg Infect Dis 2005;11:1987-1988.

20. CDC. Human vaccinia infection after contact with a raccoon rabies vaccine bait-Pennsylvania, 2009. MMWR Morb Mortal Wkly Rep 2009;58:1204-1207.

21. Masson E, Aubert MF, Rotivel Y. Human contamination by baits for vaccinating foxes against rabies in France [in French]. Sante Publique 1997;9:297-313. 